\title{
Negative Regulation of Receptor Activation
}

National Cancer Institute

\section{Source}

National Cancer Institute. Negative Regulation of Receptor Activation. NCI Thesaurus. Code C40703.

Any intercellular signaling process that reduces the frequency or extent of binding of a cognate ligand to an intracellular or transmembrane receptor to initiate an intracellular response. Receptor inhibition is involved in numerous processes, including metabolism, immune response, sexual development, nervous system function, and regulation of circadian rhythms, mood and behavior. 